\title{
El hombre sin el ser: ampliación antropológica del pensamiento de Jean-Luc Marion*
}

\section{The Man Without the Being: Anthopological Extension about Jean-Luc Marion's Thought}

\section{Wílfer Alexis Yepes Muñoz}

Referencia para citar este artículo: YEPES MUÑOZ, W. A. (2013). "El hombre sin el ser: ampliación antropológica del pensamiento de Jean-Luc Marion”. En: Revista Guillermo de Ockham 11(2). pp. 187-195.

\section{Resumen}

Este estudio analiza la posibilidad de encontrar una forma distinta de mirar lo humano a partir del concepto de fenómeno saturado de Jean-Luc Marion. Por ello, la antropología negativa se instaura en las categorías de contraexperiencia y finitud, derivadas de la experiencia mística de Dios.

Palabras clave: hombre, Dios, antropología negativa, fenómeno saturado, teología mística.

\section{Abstract}

This study analyzes the possibility of finding a different way to study the human based on JeanLuc Marion's concept of Saturated Phenomenon. Therefore, the negative anthropology is included in the categories of against-experience and finiteness, derived from the mystical experience of God.
Keywords: man, God, negative anthropology, saturated phenomenon, mystical theology.

\section{Introducción}

Ha muerto el Dios de la metafísica, el Dios de la escolástica, ha entrado en la noche, ha dejado de iluminar el horizonte sobre el cual los hombres equipararon su donación con la aletehia del ser parmenídeo que pasó a ser en Platón la eidos; en Aristóteles, la sustancia y en Santo Tomás, la identidad Ser-Dios. Pero esa muerte es la muerte de Dios como ser, es decir, de Dios como ídolo.

El revivir ese problema filosófico constituyó un escándalo para una experiencia de la fenomenología que tuvo una pretensión científica. Sobre esta visión positivista se abrió un escándalo liderado por el filósofo francés Dominique Janicaud,

- Fecha de recepción del artículo: 31-07-2013 • Fecha de aceptación: 27-08-2013

WíLFER ALEXIS YEPES MUÑOZ. Doctorado en Filosofía. Magíster en Filosofía (grado honorífico), filósofo y Licenciado en Filosofía y Letras por la Universidad Pontificia Bolivariana, sede Medellín. Docente de cátedra en la Facultad de Filosofía de la Universidad Pontificia Bolivariana (Medellín) y de Filosofía en EDUCAME (Secretaría de Educación de Medellín). Su investigación se centra en literatura contemporánea, la filosofía francesa del siglo XX y la filosofía de la educación. Correo electrónico: waymes4@hotmail.com.

* Este artículo corto en el área de la filosofía constituye la propuesta final de un curso de maestría en Filosofía y el proyecto de investigación "El pensamiento de Jean Luc-Marion", adelantado con el ánimo de construir una propuesta antropológica ampliando el concepto de "fenómeno saturado" en un análisis sobre la condición humana como búsqueda. El proyecto fue avalado por la Universidad Pontificia Bolivariana de Medellín. Fecha de inicio: marzo de 2013. Fecha de finalización: mayo de 2013. 
quien publicó un libro titulado El giro teológico de la fenomenología francesa. Al respecto, Restrepo (2010) explica:

Con este título, el autor enfilaba sus críticas contra algunos filósofos del contexto francés que, solapados -según él- en la "ciencia estricta" proyectada por Husserl, habría inusitado retorno hacia conceptos y cuestiones de cuño teológico, en lo que resultaba ser una ampliación abusiva del título "fenomenología". Leídos bajo la influencia de Heidegger, los nombres de Emmanuel Lévinas, Jean-Luc Marion y Michel Henry son los principales blancos hacia los que se dirige el ataque (p. 116).

Ese fue el escandaloso pero admirable camino recorrido por Marion hacia un giro teológico de la fenomenología y amparado por el concepto de fenómeno saturado como lo expone Walton (2010): "Hay un exceso de intuición y, por tanto, un exceso de donación, es decir, una sobreabundancia intuitiva" (p. 138). Ese escandaloso giro que destruye el ídolo para enfrentarnos a la excedencia puede entregarnos un hombre específicamente teológico ${ }^{1}$, es decir, un hombre sin el ser y con una experiencia de Dios como fenómeno saturado. Sin embargo, debemos aclarar que este fenómeno saturado no hace del hombre un fenómeno saturado, aunque desprende de él una descripción teológicoantropológica inscrita en una mística anterior a la teología escolástica vinculada a una experiencia que satura nuestro pensar: "El pensamiento místico está 'contaminado' por Dios: como centro de la historia, como razón de ser de la vida y también de la mente" (Vargas, 2011, pp. 20-21).

El exceso de donación ligado a la experiencia mística de Dios pone de relieve a un Dios en el plano de la excedencia y el acrecentamiento ( $C f$ r. Walton, 2010, p. 138). El hombre se encuentra en el plano de la indigencia, la falta y la necesidad de Dios. No sería ya un fenómeno pobre de intuición.

Tendríamos que matar otro ídolo: el hombre como único ser que por naturaleza siente necesidad del ser (Cfr. Aristóteles, p. 980a), incluso un hombre justificado por un ser, una esencia metafísica; un ídolo descalificado por la caída de los grandes metarrelatos y tal vez incluido en la fenomenología como correlato a fin de ganar una experiencia más humana y teológica. Luego, debemos responder a una pregunta: ¿qué lugar ocupa el hombre en la experiencia de Dios como fenómeno saturado? Para lograrlo, asentamos nuestra perspectiva en la propuesta de Marion con la siguiente fórmula: Dios como Dios, es decir, un Dios sin el ser. Luego, en la destrucción del ídolo por medio del juego de la indiferencia ontológica, que nos conducirá a la experiencia de Dios en el amor y, finalmente, a una antropología negativa con sentido teológico, soportada en la propuesta del autor mencionado.

\section{Dios como Dios}

Existen varias operaciones para entender esto. Una está emparentada directamente con el principio de identidad aristotélico, lo cual equivaldría tomar a Dios como Dios, sin analogías con conceptos metafísicos que terminan por tender sobre él un velo; de eso no se trata nuestro ejercicio y tampoco de una operación lógica y gnoseológica. Lo que pretendemos es, precisamente, desenmascarar esos conceptos que han negado a Dios (1) como Dios (2) y desenmascarar implica buscar en el trasfondo del crepúsculo de los ídolos. También nos exige trazar una búsqueda en la denuncia heideggeriana de la onto-teología. Es preciso asumir a Dios como "[...] el Dios de Israel, el Dios encarnado, o, sumariamente expresado: aquel ante el cual se puede danzar y hacer sacrificios" (Vargas, 2011, p. 17).

Ese Dios (1) de la metafísica no puede coincidir con la idea del como Dios (2). Así entendemos a ese Dios sin el Ser de Marion, que ya no coincide con el ídolo conceptual de la metafísica; ese Dios hay que matarlo. Hay que matar esa identidad tomista, racionalista y filosófica que tanto nos ha separado de Dios como Dios. Por su parte, el Restrepo (2012) interpreta en Marion una especie de remoción del ser partiendo de la superación de la metafísica:

1. En este punto de la reflexión, es preciso anotar que ya en Husserl -y no exclusivamente en lo que denominan giro teológico- encontramos esa caracterización de Dios como fenómeno. Al respecto plantea Vargas Guillén (2011): "Pensar a Dios, pensar sobre Dios, pensar sobre la experiencia humana de Dios como fenómeno, pensar sobre el sentido del título Dios en los procesos de fundamentación de la filosofía fenomenológica, pensar sobre el alcance de la experiencia comunitaria de la experiencia humana de Dios como fenómeno, pensar en Dios como título intencional último del proyecto teleológico de la experiencia humana de la historia: son todos enunciados que se derivan de las tres caracterizaciones que se han mostrado como notas provenientes, preliminares, de la presencia del título Dios en las obras de Husserl” (p. 33). 
Para Jean-Luc Marion, la superación de la metafísica efectivamente pasa por el cuestionamiento de la onto-teología. Pero este no se garantiza por un retorno -en sí mismo metafísico- de la cuestión del Ser, sino por esa alternativa que más bien exige y autoriza reformular la cuestión de Dios en otro distrito que el de la metafísica (p. 84).

Un Dios ya muerto, el Dios de Nietzsche; incluso el Dios que coincidió por mucho tiempo con el ser -el dios de la ontoteología- abre su paso a la auténtica experiencia Dios, a una experiencia sin idolatría; más aún, sin manipulaciones metafísicas. Pero también tenemos que desenmascarar la denuncia heideggeriana de la ontoteología ${ }^{2}$. En efecto, no se trata de un único olvido, como lo plantea Heidegger (1995): "La historia del Ser comienza, y además necesariamente, con el olvido del Ser" (p. 271).

Podemos también leer la ontoteología como un olvido de Dios. Una equivalencia de Dios con el pensamiento que se tiene de Él es un olvido de Dios. En otras palabras, del ídolo Dios, del ídolo Dios-Ser. Y el conocimiento no es más que esa idea poseída, dominada; esa especie de autoconciencia hegeliana. La perspectiva de Heidegger (2000) es clara cuando define el conocimiento como "[...] comportamiento y aquella actitud del representar por la que se aprehende lo verdadero y se lo conserva como posesión" (p. 386). Equivale a la suma de intentos de poseer a Dios, de tenerlo a la mano como el becerro adorado por Israel antes de la experiencia de Dios vivida por Moisés en el monte santo. Hace mucho tiempo, Dios era un concepto equiparable al Ser, un concepto dominado; tal vez un concepto sin experiencia.

Para la ontoteología no es posible un Dios sin el ser. En este caso, estos dos conceptos son equivalentes. No se trata, por tanto, de un único olvido, sino de un doble olvido. Lo digo porque desechar a Dios de la construcción de una ontología fundamental equivale a caer en el prejuicio heideggeriano de superar la metafísica con un pensamiento renovadamente metafísico. Sería volver a la metafísica sacando a Dios del camino para desplegar ese Ser. Claro está, su crítica nos recuerda también el olvido de Dios, que no resuena tan fuertemente como el Dios de Marion. Por tanto, tenemos que renunciar al olvido de Dios.

Cosificar a Dios significa perder la oportunidad de vivirlo como don y no como un pensamiento que lucha por conquistar una cima. Luego, habría que tachar a Dios (1) para la lograr el como Dios (2), es decir, la frase sin el ídolo Dios como Dios, teniendo en cuenta la explicitación mariana:

Bajo el título Dios sin el ser no intentamos insinuar que Dios no es, ni que Dios no es verdaderamente Dios. Intentamos meditar más bien lo que $\mathrm{F}$. W. Schelling llamaba «la libertad de Dios respecto a su propia existencia». O dicho de otro modo, intentamos poner en cuestión una evidencia que sostienen tanto los filósofos surgidos de la metafísica como los teólogos surgidos del neotomismo: Dios, antes que cualquier cosa, tiene que ser. Ello quiere decir que, antes que los otros entes, Dios tendría que tomar la iniciativa de ser. Pero, ¿acaso el ser se relaciona, más que cualquier otra cosa, con Dios? (Marion, 2010, p. 18).

Dios como ser es un ídolo. Dios como Dios significa superar el ídolo, matar el ídolo, desechar el ídolo. Es necesario un crepúsculo de los ídolos no para que Dios sea, sino para que tengamos una verdadera experiencia de Dios. Y la verdadera experiencia de Dios excede nuestras facultades, las rebasa; sobrepasa incluso el concepto de ser. La experiencia de Dios es humana y en ella el rebasamiento y la sobreabundancia entran en el corazón del hombre como una excedencia de sentido ( $C f$ r. Vargas, 2011, p. 37). Un corazón que ya no puede ver, un corazón cegado por la intuición, un corazón que ya no exige la diferencia hombre-Dios, serDios, idea de Dios-experiencia de Dios.

Dios queda tachado, porque ya no es el dios del hombre racional, el dios mirado por la razón, el dios hablado por el hombre, pensado por el hombre, creado por el hombre. Es simplemente Dios, un Dios negado como becerro de oro, como creatura a imagen y semejanza del pensamiento y a la cual el pensamiento le dobla su rodilla. Por ello Marión remueve el ser (Cfr. Restrepo, 2012):

La cruz no indica que Dios deba desaparecer como concepto o que deba intervenir tan sólo a título de

2. Frente a esta remoción del ser, esto es, frente a esta salida de la ontoteología vinculada a la metafísica, el Vargas (2011) plantea: "Se ha vuelto un lugar común hablar de ontoteología. Aparentemente es ello lo que conduce a perder el horizonte de la metafísica misma puesto que, según esta interpretación, se abandona el Ser como su asunto o, si se quiere, el ente; y, en cambio, se entroniza como pregunta, como tema y como problema a Dios" (p. 17). Para nosotros es aparente, porque no se trata de un único olvido. 
hipótesis en trance de validación, sino que lo impensable sólo entra en el campo de nuestro pensamiento haciéndose impensable por exceso, es decir, sometiendo a crítica nuestro mismo pensamiento: tachar a Dios, de hecho, indica y recuerda que Dios tacha nuestro pensamiento porque lo satura; o mejor, que sólo entra en nuestro pensamiento obligándolo a criticarse él mismo (Marion, 2010, p. 78).

Tachar a Dios es una operación paradójica. La razón construye sus propias representaciones; aquellas que no terminan por coincidir con lo que la excede o la tacha: por ejemplo, Dios. Nuestra fórmula, empero, es clara con ese tachón. Tachamos el ser, lo ontológico, la metafísica y acudimos al como Dios, a la remoción del ser, el tachón en el que Dios se dona. Esto tendría como consecuencia una ampliación antropológica que ya no suma las partes del hombre como un rompecabezas dominado y, en cierta medida, manipulado. Es volver al hombre y a Dios, divinizar una experiencia de desarraigo de lo propio o de lo que llamamos propio-insistimos en la autoconciencia-, exaltarlo en la donación de Dios y sobre todo remover un ídolo: el hombre ilustrado, el hombre que veía la religión dentro de los límites de la mera razón, el hombre que intentaba superar las tinieblas de aquel Medioevo que excedía sus facultades, a Dios como ídolo, una especie de obstáculo de experiencias netamente humanas, o terrenales. Pero, ¿acaso lo netamente humano está cerrado sobre un antropocentrismo?

Cuando el logos decidió alejarse de Dios vislumbró esta experiencia como un reflejo de sí mismo. Los maestros de la sospecha son hijos de ese ídolo, son los amantes adorados de ese ídolo antropológico: el hombre moderno. Cuando el logos apofántico decidió iluminar un mundo de dioses con la libertad del pensamiento también fracasó; se olvidó de sí mismo. Díez (2010) lo explica de la siguiente manera:

El hombre moderno que esperaba, con la autonomía de la razón, liberarse de sus creencias, terminó creyendo, con una fuerza inusitada, que con el despliegue de sus facultades podía edificar plenamente su vida. Confianza que sostuvo el avance del poder técnico-científico durante muchos siglos. Sin embargo, hoy comienza a dudarse que el hombre pueda por sí mismo realizar "algo bueno" (p. 154).

Pero esa libertad de pensamiento también nos puede regresar a la casa del Padre. De hecho, tachar a Dios implica regresar a Dios, avergonzarnos de besar becerros de oro o conceptos alados para entrar en el monte santo. Tachar a Dios es, en otras palabras, permitir que Dios mismo tache nuestro pensamiento con su exceso de donación. De hecho, el olvido de Dios, sacado de la ontoteología implica también un olvido del hombre.

Humanizar el hombre significa volver a Dios y por consiguiente, desenmascarar el ídolo hombre. Un hombre que para ser, necesita o exige negar a Dios, porque sabe que lo excede y lo tacha. Pero Dios no es un obstáculo; por el contrario, Dios nos humaniza y nos reúne al tachar nuestro pensamiento. Dios es lo impensado, lo no visto, el don, el amor (Cfr. Marion, 2010, p 79). Por ello, este volver a Dios nos reclama borrar la diferencia ontológica. ¿Con qué otra diferencia nos encontraremos?

\section{La indiferencia ontológica}

Para nuestro cometido, no es suficiente una crítica a la ontoteología. De hecho, el pensamiento de Marion en Dios sin el ser precisa el desenmascaramiento de un elemento fundamental para la ontoteología. Nos referimos particularmente a la diferencia ontológica arraigada en la incompatibilidad que busca Heidegger entre estos dos conceptos dispares: Dios y el Ser. En nuestra perspectiva, el olvido del ser incluye una diferencia $\mathrm{y}$ una indiferencia.

En primer lugar, se trata de la diferencia entre los entes particulares -los ens creatum- y Dios como creador. Esa diferencia marca el pensamiento ontológico de Tomás de Aquino que aspira agrupar los elementos de la realidad en conjuntos de conceptos cerrados en sus diferencias. Dios sería la única causa de esas diferencias, aunque eternamente diferente. Dios es diferente del mundo y del hombre; es el ser distinto, el ser superior del que prorrumpen todos los seres. Y todos esos seres mirados en ese principio no pueden violentar una ley de la teología tomista: la diferencia ontológica. El pensamiento de Heidegger se desprende de esa equivalencia lógico-gnoseológica y su reflexión continúa suspendida en la diferencia ontológica y en las posibilidades que agita el Dasein abandonando a Dios. Pero esta perspectiva termina siendo para nosotros una oportunidad. Suprimimos el 
Dios de la ontología y con él la diferencia ontológica. Por su parte, Marion lo explica con el nombre de hipoteca ontológica, no sin antes recordarnos el juego de la diferencia ontológica:

Precisamente, el juego del ser (y también el del Ser del ente) se juega según la diferencia ontológica, pensada o impensada como tal, en la separación del ente respecto al Ser o, cuando menos, en la inclusión de los entes en una ontología, incluso en una ciencia del on; el on, tomado como el ente, solo se enuncia en este juego según una diferencia que lo reconduce, en tanto que ente, al on tomado como el Ser; de manera que el ente solo el Ser que, a través de él se encara siempre a sí mismo. Un juego de la diferencia ontológica como pliegue, pero sobre todo como repliegue del Ser/ente sobre su espectáculo invisible (¿otro ídolo?). Si así se juega el juego, ¿qué implicaría, entonces, desbaratarlo dejando así de jugar? Sin duda alguna, eso implicaría jugar sin la diferencia ontológica; señalemos al punto que semejante juego sin la diferencia ontológica no coincide con el no-pensamiento metafísico de la diferencia ontológica, ya que pensar en la diferencia ontológica sin pensarla a ella misma, a la manera de la metafísica, implica evidentemente que se piense siempre a partir de ella (ibíd., p. 127).

Marion recurre también al juego de la superación apelando a la crítica de Heidegger:" "Así, en 1951, en Zürich, cuando se le preguntó una vez más: «¿Es lícito postular como idénticos ser y Dios?», Heidegger respondió: "[...] Ser y Dios no son idénticos y yo nunca intentaría pensar la esencia de Dios por medio del ser" (ibíd., p. 98). Recurrir a Dios como Dios coincide con la superación de la superación; es decir, negar a Dios como ser, suprimir las diferencias que prorrumpen de esta visión ontoteológica en la que el Ser ha sido elevado más de la cuenta y en la que ciertamente Dios se abaja al ídolo.

La diferencia ontológica es una operación idolátrica; una experiencia de idolatría de la razón pura, la razón que es causa de su mismo Dios, del ídolo-Dios encumbrado como objeto supremo en un plano nouménico que ella misma nombra. ¿Se trata de conocer a Dios? ¿A qué Dios nos referimos?
Existe una especie de indiferencia ontológica en este retorno al suelo de creencias. La indiferencia consiste en que el ya gastado concepto de Ser gastado en su olvido y en el subsiguiente olvido de Dios- queda excluido.

Tomar a Dios como Dios consiste en borrar la diferencia ontológica. Ya es indiferente la diferencia; estamos por fuera de ella, aunque buscamos en Dios algo más, algo en él que pueda mirarnos. Con Marion entramos en el terreno de lo impensable o por lo menos, en un ámbito que es vivido y no agotado por nuestro pensar; un terreno en el que el pensar que juega a la diferencia es tachado: "Tachamos el nombre de Dios para poner de manifiesto, ante nosotros mismos claro está, que su impensable satura nuestro pensamiento, desde el origen y para siempre" (ibíd., p.78). En este sentido, tachamos para que no sea el ídolo, sino Dios realmente quien se dona por el amor:

En consecuencia, pensar a Dios fuera de la diferencia ontológica, y fuera también de la pregunta por el Ser, corriendo el riesgo de lo impensable, indispensable pero insuperable. Sin embargo, ¿qué nombre, qué concepto y qué signo podemos entonces practicar? Sólo uno, sin duda, el amor, o como se lo quiera llamar, tal y como propone San Juan «Dios [es] agapè» (I Juan 4,8). ¿Por qué el amor? Porque este término, que tanto Heidegger como toda la metafísica -aunque de otra manera- mantienen en un estado derivado y secundario, sigue siendo todavía de manera paradójica lo suficientemente impensado como para liberar, algún día al menos, el pensamiento de Dios de la segunda idolatría (ibíd., p. 79).

En la experiencia, Dios es tachado como Ser renunciando al terreno de lo objetivado. Pero, ¿quién es objetivado? El hombre como recipiente. Cabe aclarar que esta objetivación humaniza la experiencia del hombre en Dios. Y la humaniza por el amor no como acontecimiento secundario de su excedencia. El amor pasa a ser ese lenguaje, el lenguaje de la exaltación, de la plegaria, la acción de gracias y la vida de la gracia. Y elegimos el amor por una sencilla razón: "El amor ama sin condición, por el simple hecho de que ama.

3. Esta idea podemos complementarla con el siguiente fragmento de Dios sin el ser: "En cierto sentido, es precisamente Heidegger quien advirtió que hay que liberar a «Dios» de la pregunta sobre/por el Ser, aunque esta liberación contraviene también las condiciones del pensar. La magnitud de nuestra proposición -liberar a «Dios» del Ser- sólo resulta tolerable y, por tanto, digna de consideración, si la formulamos primero rigurosamente para admitir las reservas precisas y para ofrecer así una paradoja a su justa medida. Debemos, pues, seguir la instauración heideggeriana del quiasmo entre «Dios» y el Ser, aunque sólo sea para aprender a desplazarlo" (ibíd., p. 98). 
Ama también sin límite ni restricción" (ibíd., p. 79). Ahora bien, ¿qué otro elemento nos permite avanzar a esa superación teológica de la metafísica?

\section{La experiencia de Dios}

La experiencia de Dios en la superación teológica de la metafísica no coincide con la relación sujeto-objeto. No concierta con una experiencia a ultranza de las ideas adventicias cartesianas y en general de la razón ilustrada. Tampoco de un Dios que coincide con el ser y el juego de la diferencia ontológica, que lo define como causa incausada, es decir, como un objeto más de nuestra necesidad de saber. No se trata de un ídolo, de un becerro vacío, pobre, que solo el hombre puede mirar, tocar y manipular. En este sentido, estamos de acuerdo con lo planteado por Arboleda (2009) acerca de la ontoteología:

La ontoteología fija, explica y fundamenta. De allí dos de las críticas que se le hacen. Es fisicalista y violenta. En cuanto fisicalista produce la sensación de lo cristalizado, endurecido, que no cambia y con una existencia real cosmológica o conceptual. En cuanto violenta, establece una sola verdad que ha de ser aceptada por todos y que se impone a todos, sin posibilidad de más perspectivas (p. 232).

La ontoteología niega la experiencia, su desinterés, la vida ascética, el misticismo, la revelación y más bien está atenta a sus diferencias endurecidas y a su cristalización de lo que es Dios para nosotros: un ser simple, un concepto más del stock de la metafísica, un concepto sellado y ubicado en la parte más alta de los valores ontológicos. De este modo, excede la interesante teología del Doctor Angélico que no está libre de esa violencia fisicalista. Pero, ¿cómo lo logra Marion?

Marion logra la superación de la superación con el fenómeno saturado, que amplía el concepto de fenómeno. De ahí que la crítica de Dominique Janicaud valore como escandaloso el hecho de incluir a Dios en las discusiones fenomenológicas. Sin embargo, Marion (2008) propone esta categoría sobre el fondo de una filosofía que ha olvidado a Dios con su violencia y fisicalismo, ampliando así el horizonte de la fenomenología y con él la experiencia de Dios: "Ni mentable según la cantidad, ni soportable según la cualidad, absoluto según la relación, es decir, incondicionado por el horizonte, el fenómeno saturado se caracteriza finalmente como inmirable según la modalidad" (p. 348).

En efecto, el fenómeno saturado no coincide con las categorías de la metafísica. Más bien, sobrepasa la concepción kantiana y husserliana de fenómeno como lo explica Marion: "El fenómeno se caracteriza pues, según Husserl y Kant, por la falta de intuición en él, que no lo da más que limitándolo" (ibíd., p. 321).

Marion desarrolla una propuesta postmetafísica en tanto posibilita el regreso a la casa del Padre. Ya no se trata de una experiencia dominada por la razón y una intencionalidad de fenómenos de derecho común que "son los objetos del mundo percibido, las ciencias de la naturaleza y la técnica" (Walton, 2010, p. 138) o fenómenos pobres de intuición "en que la intención significativa anticipa la intuición" (ibíd.). Dios es lo inmirable. Por consiguiente, la transformación de las categorías kantianas demarcan una especie de teología negativa que sitúan a Dios en el marco de lo noobjetivable. Dios no es un objeto más de la razón, no es algo que podamos calcular como los objetos del mundo percibido. En nuestra perspectiva, estos son fenómenos necesarios para orientarnos en el mundo que no pueden ajustarse a la experiencia de Dios. El fenómeno saturado supera la experiencia idolátrica y nos instala en el plano de la mística. De hecho, la explicación de Marion (2008) hace visible ese volver al suelo de creencias a partir del fenómeno saturado:

En consecuencia, el fenómeno saturado no puede preverse por, al menos, dos motivos fenomenológicos. a) Por una parte, porque la intuición que lo satura sin cesar impide distinguir y adicionar en él un número finito de partes finitas, anulando así toda posibilidad de pre-ver el fenómeno antes de que se dé en persona. b) Por otra parte, porque el fenómeno saturado se impone la mayoría de veces gracias al asombro, en el que la no-recensión de sus eventuales partes y también la imprevisibilidad son precisamente las que cumplen toda la donación intuitiva (p. 333).

Si comparamos la experiencia de Dios como fenómeno saturado con la experiencia de los fenómenos de derecho común y los fenómenos pobres de intuición que son objetivables y medibles, esta experiencia se traduciría en una contraexperiencia, incluso en una experiencia negativa que tacha 
nuestro pensamiento y nos sitúa en el límite: somos mirados y solo podemos alabar o elevar una plegaria. En este sentido, el concepto de experiencia tiene que ser revaluado:

La contraexperiencia no equivale aquí a una no experiencia, sino a la experiencia de un fenómeno no mirable, no mantenido bajo la objetidad, un fenómeno que resiste a las condiciones de la objetivación. La contraexperiencia ofrece la experiencia de lo que contradice irreductiblemente las condiciones de la experiencia de los objetos (ibíd., p. 350).

En esta experiencia no hay horizontalidad, ni encuentro, ni equilibrio. Somos rebasados o mirados; nos encontramos en el límite; se nos revela nuestra finitud al tiempo que Dios se dona. Con el fenómeno saturado tomamos conciencia de nuestra humanidad, una humanidad excedida por Dios. Los fenómenos pobres de intuición no nos revelan lo que somos realmente; por el contrario, el fenómeno saturado hace visible nuestra verdadera herencia: la de sentirnos hijos a pesar de nuestra pobreza. Y en esa experiencia rebasada la intuición es soberana, a diferencia de los fenómenos pobres de intuición en los que el concepto es rey: "En el reino del fenómeno, el concepto no es el rey, sino más bien la intuición que es la única que dispone del privilegio de dar" (ibíd., p. 319).

Finalmente, hemos destruido el becerro de oro a fin de acoger la intuición donadora ( $C f r$. Id.: 351), una intuición de la contraexperiencia, es decir, de la experiencia que es mirada por Dios; una experiencia que es la evidencia sin violencia, la evidencia del hombre desde Dios y a partir de Él. Y en este exceso solo podemos alabar y hasta a veces callar ya que no se trata de una experiencia cognoscitiva sino mística, como lo explica Arboleda (2010): "Esto coloca al hombre en estado de no conocimiento donde ocurre la experiencia de unión silenciosa con lo divino" (p. 183).

Siguiendo la propuesta de Marion (2008), el fenómeno saturado que refleja más auténticamente esta experiencia mística y negativa es el icono, modificando así las estructuras modernas de un conocimiento basado en las intenciones del sujeto, en su mirada fisicalista y violenta de los objetos:

Nombraremos a este último tipo de fenómeno saturado "icono" porque ya no ofrece ningún espectáculo a la mirada, ni tolera la mirada de ningún espectador, sino que ejerce inversamente su propia mirada sobre el que lo encara. El que mira toma el lugar del que es mirado, el fenómeno manifestado se invierte en una manifestación no solamente en y de sí, sino estrictamente por y a partir de sí (automanifestación). La paradoja invierte la polaridad de la manifestación tomando la iniciativa y no recibiéndola; dándola y no dándose (p. 375).

La experiencia de Dios se invierte con el icono. El hombre simplemente se abandona a la contemplación. Es el recipiente de la gracia, del amor y de un discurso de alabanza que no se ufana de sus conquistas. Sin embargo, constituye una experiencia negativa no solo de Dios, sino también del hombre. Sobrecoge el misterio del hombre oculto a una visión ontoteológica que niega la experiencia. No niega el hombre, pero niega todo aquello que el hombre pretende con su pensamiento: poseer y saber.

No sabemos de Dios, no explicamos lo que sucede en el ámbito de una teología mística. En ella prevalece la contemplación sobre el emplazamiento conceptual. De hecho, somos consagrados por Dios a la vida de la gracia, nos hacemos sus hijos, entramos en un misterio que nos excede; hablamos para bendecir, nos hacemos testigos de ese don infinito que tacha y rebasa nuestra finitud. Así nos hacemos humanos por la experiencia de Dios y nos asemejamos más al místico que al científico.

\section{Conclusiones}

La hipótesis que defendimos a lo largo de este estudio es que el giro teológico constituye un giro antropológico-teológico de la fenomenología. No de la conciencia como correlato, sino del hombre que se hace total en la experiencia de un fenómeno religioso saturado que enriquece su falta y su finitud. En este sentido, la ampliación antropológica cobra importancia en nuestra interpretación de ese Dios que se dona en exceso $\mathrm{y}$ de ese hombre particular; de ese hombre que mata el ídolo hombre liberando así su indigencia, incluso sobresituándola en una experiencia límite que diviniza su finitud. Ya no se trata de buscar al hombre o la verdad del hombre, sino de humanizarlo en la experiencia límite de la excedencia y la sobreabundancia de Dios.

Debemos aclarar que el fenómeno saturado no hace del hombre un fenómeno saturado, pero 
puede desprender de él una descripción teológica del hombre inscrita en una mística anterior a la teología escolástica. En efecto, el exceso de donación ligado a la experiencia mística de Dios, pone de relieve un Dios en el plano de la excedencia y el acrecentamiento (Cfr. Walton, 2010, p.138). Un acrecentamiento logrado por la teología mística de Dionisio Areopagita y en la que el hombre se hace místico por la experiencia de Dios:

La experiencia de los místicos no es expresada en conceptos de Dios sino en símbolos que dicen algo y no dicen todo de lo que sería la realidad absoluta, o la realidad. La nueva filosofía francesa, especialmente, acepta las críticas a la ontoteología, pero también quiere ir más allá: buscar una filosofía (y luego una teología) sin referencia al Ser, en la línea de Dionisio Areopagita. Una filosofía que no sea idolátrica, estática y conceptual, sino que vaya al darse radical del fenómeno (Arboleda, 2010, p. 185).

Nuestra tarea consistió en matar un segundo ídolo: el único ser que por naturaleza siente necesidad del ser; un hombre justificado por su ser, el ser buscado en el conocimiento. Un ídolo descalificado por la caída de los grandes metarrelatos y tal vez incluido en la fenomenología como correlato para ganar una experiencia más humana y teológica. Lo humano no está ligado únicamente al conocimiento, sino a la experiencia. Y una experiencia es una lectura en la cual el lector pasa a ser el leído, como lo explica bellamente Larrosa (2003), contraponiendo la experiencia moderna a una experiencia del hombre que en cierta medida es mirado: "La experiencia es lo que nos pasa, o lo que nos acontece, o lo que nos llega. No lo que pasa, o lo que acontece, sino lo que nos pasa, o lo que acontece, o nos llega” (p. 87). El hombre es también la experiencia de Dios, el Dios que pasa, acontece y llega a su vida para colmarla. Un Dios que es donación sin medida, un amor que excede las diferencias, la reconciliación que eleva nuestra humanidad sedienta de él, hambrienta de ser mirada por él. Un Dios que a fin de cuentas es una experiencia humana de Dios.

Concluyamos. La experiencia de Dios por medio del fenómeno saturado nos permite recoger todos los trozos de humanidad que nos ha entregado la historia: los fenómenos pobres de intuición que hemos sido para la metafísica; los fenómenos de derecho común que ha utilizado la modernidad para convertir su experiencia en una nueva idolatría. Pero rompiendo todos nuestros becerros, incluso negando nuestros intereses de posesión en el conocimiento y la técnica, nos humaniza el hecho de ser mirados por Dios. Esto sí que constituye una fenomenología radical.

\section{Bibliografía}

- ARBOLEDA MORA, Carlos (2009). Posontología y posmetafísica en el siglo XXI. Medellín: Universidad Pontificia Bolivariana.

- _ (2010). Dionisio Areopagita y el giro teológico de la fenomenología. En: Pensamiento y Cultura, 13 (2). pp. 181-193.

- ARISTÓTELES (1994). Metafísica. Trad. Tomás Calvo Martínez. Madrid: Gredos.

- DÍEZ, Ricardo Oscar (2010). Volver al «suelo de creencias». En: Pensamiento y Cultura, 13 (2). pp. 141-155.

- HEIDEGGER, Martin (1995). Caminos del bosque. Madrid: Alianza.

- _ _ (2000). Nietzsche. Barcelona: Destino.

- LARROSA, Jorge. (2003) La experiencia de la lectura: Estudios sobre literatura y formación. México: F.C.E.

- MARION, Jean-Luc (2008). Siendo dado. Madrid: Síntesis.

- _ (2010). Dios sin el ser. Vilaboa: Ellago Ensayo.

- RESTREPO BERMÚDEZ, Carlos Enrique (2010). El «giro teológico» de la fenomenología: Introducción al debate. En: Pensamiento y Cultura, 13 (2). pp. 115-126. 

(2012). La remoción del ser: la superación teológica de la metafísica. Bogotá: San Pablo.

- VARGAS GUILLÉN, Germán (2011). Ausencia y presencia de Dios. 10 estudios fenomenológicos. Bogotá: San Pablo.

- WALTON, Roberto (2010). El giro teológico como retorno a los orígenes: La fenomenología de la excedencia. En: Pensamiento y Cultura, 13 (2). pp. 127-140. 